\title{
Visiones femeninas en torno al espacio de la obra artística y a la relación cuerpo-casa/casa-cuerpo
}

\author{
Lorena AMORÓs BLASCO \\ Facultad de Bellas Artes. \\ Universidad de Murcia \\ lorenamo@um.es
}

Recibido: 15.09 .2012

Aceptado: 30.09 .2012

\section{RESUMEN}

Desde una perspectiva iconográfica, la relación cuerpo-casa/casa-cuerpo, continúa siendo una constante discursiva en el imaginario artístico y femenino contemporáneo. Lo que llamamos hoy construcción cultural de la subjetividad femenina ya estaba presente en el trabajo de artistas, historiadoras y críticas de arte del feminismo de los años setenta. Al respecto, la presente investigación propone exponer a través de la obra de mujeres artistas (principalmente: Eulalia Valldosera y Marina Abramovic) los avances obtenidos en torno a la problemática del espacio subyugado a la estructura del hogar patriarcal, donde lo femenino se define en las actividades y en el trabajo doméstico, y donde lo público tiene valor significativo a costa de restar trascendencia al espacio de lo privado cuando se asocia a la mujer.

Palabras clave: mujer, identidad subjetiva, espacio doméstico, casa-cuerpo, público-privado.

\section{Feminine Visions Around the Space of the Artwork and the Relationship of Home-Body/Body-Home}

\begin{abstract}
From an iconographic perspective, the relation of home-body/body-home is still a common topic in the discourse on contemporary art and feminine imagery. What is known today as the cultural creation of feminine subjectivity was already present in the work of artists, historians, and art critics in the feminism of the seventies. This investigation analyzes the progress achieved through the work of women artists (mainly: Eulalia Valldosera and Marina Abramovic) in relation to the discussion on the subjugated space in the structure of patriarchal household where femininity is defined by activities and domestic work and where the public has a significant value because it diminishes transcendence the private space associated with women.
\end{abstract}

Key words: Women, subjective identity, domestic space, home-body, public-private.

\section{INTRODUCCIÓN}

Para desarrollar la perspectiva iconográfica y teórica en torno a la relación cuerpocasa/casa-cuerpo, utilizaremos a nivel metodológico el análisis de contenido, incidiendo en la obra ensayística y de comisariado iniciada en los años noventa por Amelia Jones en lo referente a las nociones de subjetividad en las prácticas del body art. Asimismo, insistiremos en las referencias a los estudios de pensadoras feministas 
quienes, como Gail Weiss, han dedicado especial atención a desarrollar nuevos términos en la concepción de la subjetividad, señalando la importancia de la creación de imágenes del cuerpo a partir de las nociones de intercorporalidad y multiplicidad. Para desplegar este trazado que pretende dar visibilidad a los procesos de construcción de la "identidad femenina" en lo relativo a la asociación de conceptos anteriormente subrayados, donde el hogar tradicional aparenta en crisis, nos detendremos en la dicotomía público-privado, que ha venido organizando en gran medida el pensamiento feminista para explicar cómo lo público tiene valor significativo a costa de restar trascendencia al espacio de lo privado cuando se asocia a la mujer. Al respecto, las obras más significativas de artistas como Judy Chicago, Miriam Shapiro, Sandra Orgel, Susan Frazier, Vicki Hodgetts, Robin Weltsch, Louise Bourgeois y Francesca Woodman, nos servirán de ejemplo para contrastar otros posicionamientos artísticos y discursivos en torno al tema central de nuestra investigación. Para abordar dicha trama, así como la relación entre los conceptos de cuerpo-casa-hogar desde una perspectiva artística más coetánea, nos centraremos en la obra Aparences (1992-1996) de Eulalia Valldosera y en la performance The house with the ocean view (2002) de Marina Abramovic. Ambos trabajos pueden entenderse como obras contrapuestas en relación a los conceptos de cuerpo-casa-hogar, así como la dicotomía público y privado que venimos remarcando.

\section{AMELIA JONES: NOCIONES DE SUBJETIVIDAD EN LAS PRÁCTICAS DEL BODY ART DE LOS AÑOS NOVENTA}

A partir de la década de los noventa, las reflexiones sobre el tema del cuerpo y la subjetividad aportan profundidad al estudio de las políticas de representación y de las políticas sexuales de la mirada que habían sido las perspectivas básicas en el estudio de las prácticas artísticas. Al respecto, la labor de crítica feminista y de comisariado llevada a cabo por Amelia Jones en la llamada "década prodigiosa" de la performance femenina es fundamental para entender la nueva subjetividad artística desde las nociones de perfomatividad y fenomenología. Asimismo, la especial atención en el desarrollo de nuevos términos en la concepción de la subjetividad femenina, contribuyó a que pensadoras como Gail Weiss señalasen la importancia de la creación de imágenes del cuerpo a partir de las nociones de intercorporalidad y multiplicidad. En el libro Body Images: embodiment as intercorporeality, Weiss dedica especial atención al estudio de estas reflexiones.

Asimismo, es importante remarcar que la toma de conciencia de lo que hoy llamamos construcción cultural de la subjetividad femenina, como sostiene Amelia Jones, ya es manifiesta en obras de Judy Chicago y alguna de sus contemporáneas, como Miriam Shapiro. Según mantiene Jones, el uso de la imaginería vaginal que sostienen estas artistas es un registro claramente político, destinado a promover 
representaciones "positivas" del cuerpo femenino, capaces de subvertir la imagen de las mujeres como fetiches y objetos pasivos de la mirada masculina. Evidentemente, se pueden plantear dudas en referencia a si este gesto tuvo o no los resultados esperados, pero lo evidente es que el "arte del coño" no obedecería a la voluntad de reducir "la feminidad" a su vertiente biológica, sino a la creencia de que era el terreno de la biología y la sexualidad donde se centraba en gran medida el proceso de configuración social de la identidad de las mujeres y, por tanto, el terreno donde había que incurrir de forma insistente. De ahí que la frase-resumen: "biología es destino" pueda entenderse, desde el punto de vista de Jones, como emblema metafórico del poder de independencia de las mujeres y su libertad respecto de la dominación masculina. Sin embargo, a pesar de partir de esta consideración, nuestra investigación no pretende limitar el común debate feminista entre las prácticas culturalistas y las prácticas deconstructivistas en la representación, sino visibilizar y debatir la eficacia o no de experiencias corporales femeninas que niegan su enunciación tradicional y apuntan a la necesidad de partir de una noción comprensiva en lo relativo a la asociación de conceptos cuerpo-casa/casa-cuerpo.

\section{EL VÍNCULO CUERPO-CASA/CASA-CUERPO EN OBRAS ARTÍSTICAS FEMENINAS}

Para desplegar el trazado iconográfico de nuestra investigación, nuestro principal objetivo será destacar la construcción del espacio de la representación concebido por mujeres artistas a partir de experiencias donde el cuerpo tiene una relevancia significativa; pues ya sea tratado de forma real/presente como de manera simbólica/ausente, en ambos casos se niega su enunciación tradicional y se apunta a la necesidad de partir de una noción comprensiva en lo relativo a la asociación de conceptos cuerpo-casa/casa-cuerpo. En este sentido, la obra Womanhouse de 1972, una de las primeras experiencias del Arte Feminista californiano de los años setenta, es significativa al respecto. Dicha obra, ideada por 21 alumnas del Programa Feminista de Arte De La Universidad De California (CalArts), entre las que se encontraban Sandy Orgel, Susan Frazier, Vicki Hogetts y Robin Weltsch, y de sus profesoras, Judy Chicago y Miriam Shapiro, consistió en la transformación de 17 habitaciones de una casa en un environment colectivo, es decir, una exposición de instalaciones y performances de las citadas artistas. En la pieza ideada por Sandra Orgel, titulada Linen Closet (Figura 1), podía verse un maniquí atravesado por las estanterías de un armario abierto donde se guarda la ropa doblada. La figura femenina desnuda, en posición de koré griega, es decir, con una pierna avanzada "saliendo del armario" tenía un doble significado. Por un lado, daba cuenta simbólicamente de cómo la casa recluye al cuerpo femenino y lo limita, dada la configuración determinista "cuerpo femenino-tarea doméstica". Y por otro, al mismo tiempo, el hecho de que el cuerpo femenino se hallase atravesado literalmente por el armario en su acto de emancipación, podría llevarnos a comentar un matiz interesante 
relacionado con un deseo emancipador: No sólo se trataría de salir del armario sino llevárselo consigo, con el fin de revalorizar las actividades del cuidado del lugar donde se habita. De esta manera, dicha liberación se convierte en un acto de pasaje que tiene valor en sí misma y se lo confiere a la historia de las relaciones tradicionales del ama de casa y de las tareas domésticas.

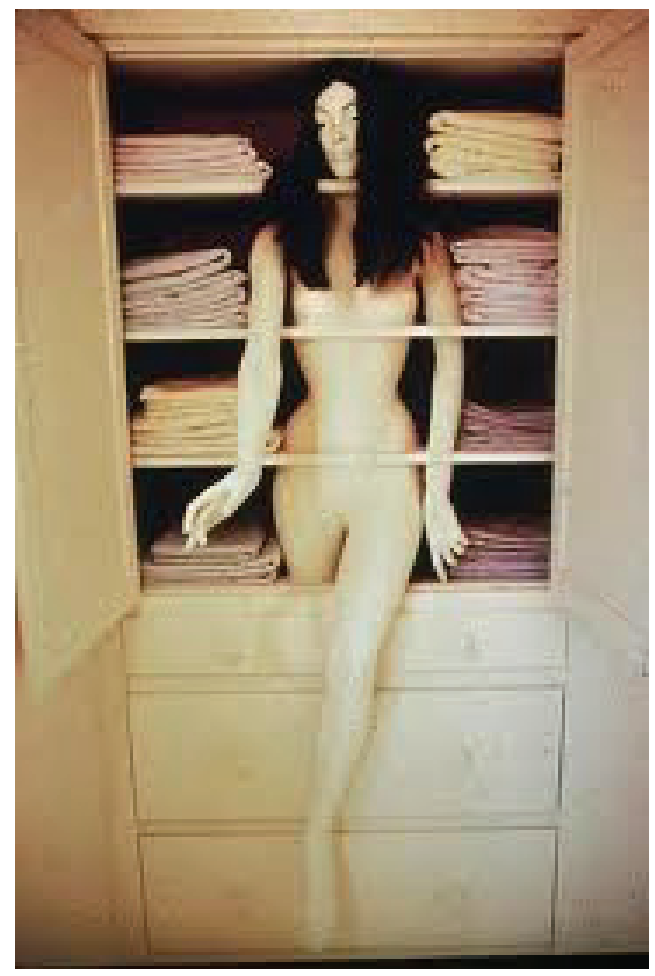

Figura 1. Sandy Orgel, Linen Closet, 1972.

Nurturant Kitchen (Figura 2), de Susan Frazier, Vicki Hogetts y Robin Weltsch, otra de las obras que conformaban el proyecto, mostraba aspectos de una relación más psicológica con el espacio de la casa. La obra consistía en una cocina pintada de rosa y decorada con formas que sugerían huevos fritos en el techo y pechos femeninos en las paredes. El ejercicio visual fue el resultado de un trabajo de análisis sobre las memorias de infancia. El espacio de la cocina simbolizaba la "zona de conflictos" entre la madre que nutre y la hija que consume y debate su autonomía. En esta obra "nos encontramos con un ejemplo de corporización femenina del espacio de la casa, tematizado, en este caso, como un cuerpo nutriente/castrante" (Bassas, 2001: 118).

Este aspecto, puede observarse asimismo, como veremos más adelante, en la obra de Eulalia Valldosera, El comedor: la figura de la madre, donde la artista señala la 
comida como rol principal y al comedor como un espacio simbólico y psicológico relacionado con la figura de la madre.

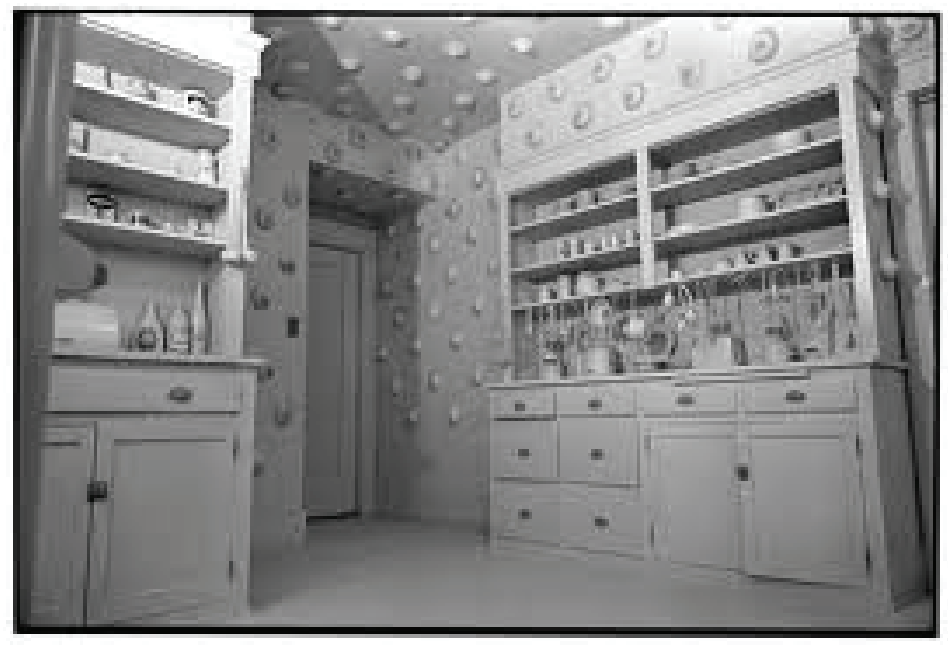

Figura 2. Susan Frazier, Vicki Hogetts y Robin Weltsch, Nurturant Kitchen, 1972

Otras artistas posteriores han trabajado sobre este vínculo que subrayamos, si bien, además, desde prismas distintos. Por ejemplo, en relación al vínculo híbrido entre el cuerpo femenino y la casa, la serie de Louise Bourgeois, titulada Femme Maison (1945-1947) sería uno de los precedentes icónicos más claros y oportunos. Concebida en términos eróticos, las obras que componen la serie tienen que ver con las dificultades de aparición del cuerpo femenino, pero también con su decisión de no objetivar el proceso de subjetivación en los términos de un lenguaje que no se ha configurado desde la experiencia compleja del cuerpo sexuado, del cuerpo erótico, del cuerpo en relación. De modo que, como puede observarse, la relación se establece en el marco de la poética. Algo similar, aunque técnicamente distinto, ocurre en el trabajo fotográfico de Francesca Woodman. En su serie House, de 1976, la artista remarca la necesidad visual de entender su cuerpo en relación a la casa desde una poética de transgresión de la realidad. En sus fotos aparece ella misma como un cuerpo etéreo, disgregado, en aparente desintegración total de su materialidad, en un intento de acceder a otro mundo, a otra realidad. La artista utiliza objetos de la casa (ventana, chimenea, espejo, puerta), como elementos visuales a partir de los cuales poder desaparecer y metamorfosearse con el espacio. Como señala Assumpta Bassas:

"Nos hallaríamos, pues, frente a una noción de subjetividad, la que se construye en la tensión entre la dependencia y la interdependencia a través de un cuerpo que tampoco reconoce los límites de su propia materialidad sino que se despliega en las cosas, se expansiona, se hace comprensivo, se experimenta en la intercorporalidad, se 
desborda continuamente hasta casi desaparecer pero reaparece también continuamente en sus singularidades, entre ellas, la diferencia sexual" (Bassas, 2001: 122).

En House 3, (Figura 3) su cuerpo aparece distorsionado bajo una ventana de una casa abandonada, y su rostro apenas se reconoce; sólo puede advertirse un zapato de infancia, conservado intencionadamente por la artista. La ventana actúa como elemento principal de análisis de la imagen. La luz que por ella entra se fusiona con el rostro de la artista, disolviéndose. Una experiencia que conjuga el espacio interior con el exterior, en el intento de traspasar las fronteras que la lleven a otro mundo. Del mismo modo, se confunde con la pared, fundiéndose con el interior de la casa, como absorbida. Esta metáfora de absorción del cuerpo femenino en el espacio privado muestra una significativa reflexión sobre la problemática del espacio subyugado a la estructura del hogar patriarcal, donde lo femenino se define en las actividades y en el trabajo doméstico. Pero en este trabajo, no sólo se alude al sometimiento de la mujer por las voluntades masculinas, sino también, a la idea de alteración de la identidad y a nuestra imposibilidad de encontrar una imagen que nos diga algo de nosotras mismas. Este planteamiento general se repite a lo largo de su obra, sobre todo en la utilización de los espacios privados, como el interior de la casa, el uso del rincón como simbología del confinamiento, o la fusión con objetos y elementos que remiten directamente a lo doméstico.

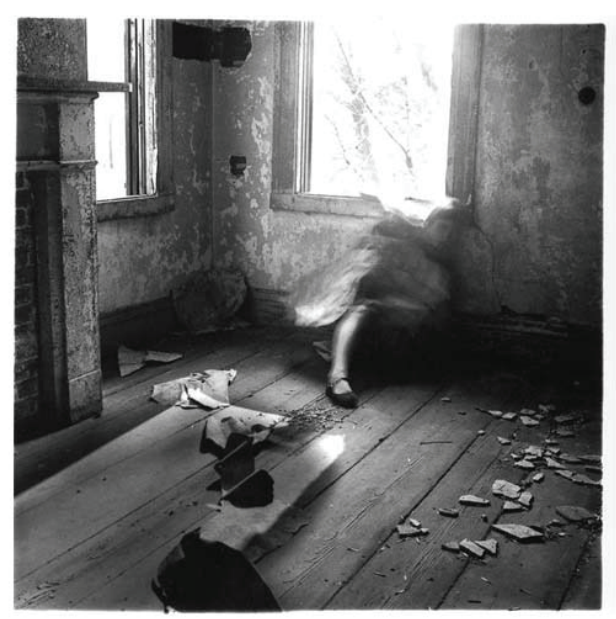

Figura 3. Francesca Woodman, House 3, 1976. 


\section{EL VÍNCULO "CUERPO-CASA-HOGAR" DESDE LA PERSPECTIVA ARTÍSTICA DE EULALIA VALLDOSERA (APARENCES, 1992-1996) Y MARINA ABRAMOVIC (THE HOUSE WITH THE OCEAN VIEW, 2002).}

Aparences (1992-1996), una instalación de Eulalia Valldosera y la performance The house with the ocean view (2002) (Figura 4) de Marina Abramovic, son dos obras que pueden entenderse como contrapuestas en relación a los conceptos de cuerpocasa-hogar, así como a la dicotomía público y privado. En el caso de Eulalia Valldosera, la referencia al vínculo cuerpo-casa no es icónica en el planteamiento inicial de su proyecto, no obstante, estructura el esquema básico de la obra: Cada una de las instalaciones se constituye como una de las habitaciones que tradicionalmente conforman una vivienda occidental, estableciendo una relación directa entre dichas estancias y el cuerpo. La serie está formada por obras como La cocina, de 1992 o El comedor: la figura de la madre, de 1994 (Figura 5).
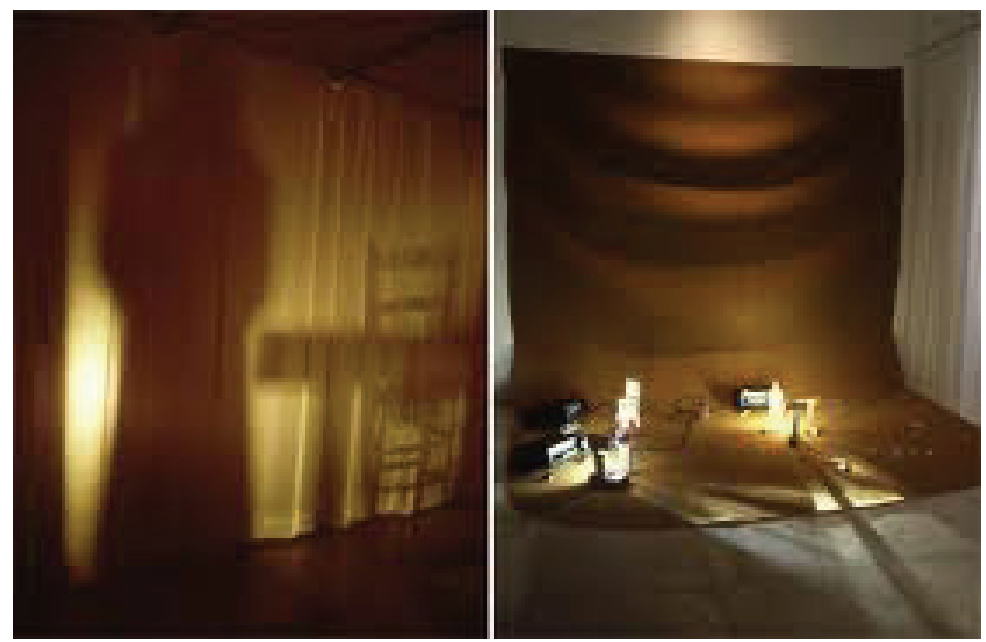

Figura 5. Eulalia Valldosera, El comedor: la figura de la madre, 1994.

Es destacable, cómo en este punto, la casa aparece referenciada por los objetos asociados al ámbito de lo doméstico que son, a su vez, metáforas y metonimias de la presencia/ausencia de los cuerpos y de los actos de proyección especular o mediática (memoria, fantasía) que desarrollan los procesos se subjetividad.

Por otro lado, en la obra performativa de Marina Abramovich, la casa sí aparece referenciada a partir de una estructura que aunque esquemática, sí alude a algún tipo de arquitectura habitable (exterior-interior). En esta estructura, la artista se impone transmitir la importancia que para ella tiene el proceso de preparación del cuerpo 
entendido como un modo de ensamblaje entre un estado físico y mental ideal, válido para la creación de un trabajo artístico. Como ella misma apunta:

"El cuerpo puede entenderse como una casa y esta limpieza de la casa consiste efectivamente en llevar el cuerpo a un estado particularmente receptivo de una energía específica, es decir, a un estado en el que sea posible la creación de un trabajo bastante potente y capaz de transformar a las personas". (Laub, 2004: 20).

De ahí que en la performance The house with the ocean view, Abramovic desee experimentar en torno a la disciplina, las reglas y las restricciones cotidianas del cuerpo con el fin de conseguir una supuesta purificación. “¿Puedo cambiar mi flujo de energía?” ¿Este flujo de energía puede cambiar el del público y el espacio en sí?” Se preguntaba la artista.

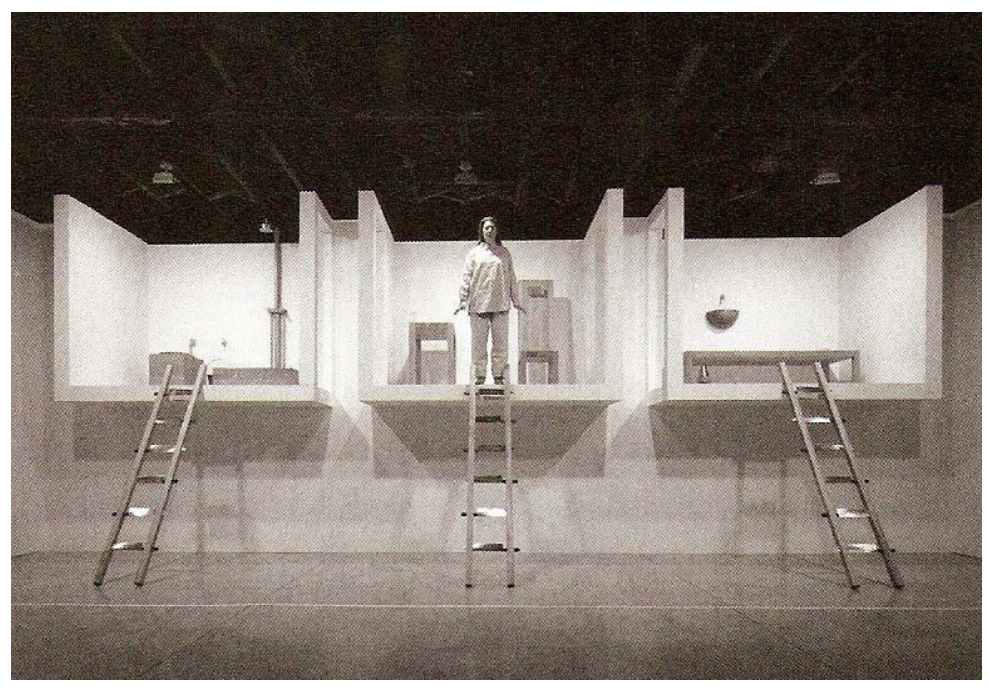

Figura 4. Marina Abramovic, The house with the ocean view, 2002.

Como podemos evidenciar, a diferencia de lo que ocurre en la obra de Eugenia Valldosera, la presencia de la artista y del público durante doce días y doce noches en la Sean Kelly Gallery de New York, era una condición indispensable para el desarrollo de la performance de Abramovic. En estos días, las reglas autoimpuestas por la artista en relación a la disciplina cotidiana del hogar como espacio donde poder purificarse, eran las siguientes:

"Condición para la instalación: artista

La prohibición de la comida para la artista 
Canciones: posibles pero impredecibles

La prohibición de la escritura

La prohibición de la lectura

Dormir un máximo de 7 horas al día

No tener limitaciones en cuanto a la posición de pie, ni en cuanto a la posición recostada

Ducharse tres veces al día

Permanecer en silencio

Duración: 12 días y 12 noches. 2002

Lugar: Sean Kelly Gallery, New York” (Laub, 2004: 97).

Abramovic presenta su cuerpo, en una conjunción donde el narcisismo adquiere grandes dosis de exhibicionismo y donde el espectador es tratado no sólo como voyeur, sino también como sujeto al que se interpela y al que se comunica aquello que no sólo forma parte de la experiencia de la artista y pertenece también a cierta memoria colectiva. Por su parte, en el mundo de Valldosera, el cuerpo es construido y percibido a través de espejos. El espejo, posee una significación muy amplia y se entiende, entre otras cosas, como el espacio en que uno proyecta sus necesidades y anhelos. Pero el espejo tal como lo utiliza Eulàlia Valldosera, introduce una suerte de disonancia o distorsión. Al proyectar las imágenes, la artista las fragmenta, las rompe, las descompone, transmitiendo la pérdida de un ideal de unidad y de equilibrio, que es paralela a otro aspecto muy importante en su obra: la disolución. Un aspecto que la acerca a la obra de Francesca Woodman, como hemos podido observar anteriormente, pero que sin embargo la distancia de la corporeidad explícita que reclama y evidencia Marina Abramovic. En Valldosera, como en Woodman, existe tanto una intencionalidad visual de fusionar el cuerpo y el espacio, como un deseo por deshacerse y fundirse con el fondo y los objetos. De ahí que sus respectivas subjetividades se fijen entre lo psíquico y lo somático. Resulta importante destacar cómo en este momento concreto, cuando la imagen se fragmenta y el cuerpo se disuelve, ambas artistas expresan la relación contradictoria con su propio deseo. El deseo, en la obra de Marina Abramovic constituye de distinto modo un intenso diálogo consigo misma en el que se reivindica la sexualidad femenina, y donde la relación entre arte y vida, es imprescindible.

En The house with the ocean view, no puede pasarse por alto la denuncia de la sumisión de los cuerpos al régimen visual del capitalismo, no obstante, Abramovic va más allá de una mera reflexión sobre los límites entre lo público y lo privado y la incomunicación en la experiencia contemporánea. En su lectura, el interior del hogar, de la casa, no significa ya intimidad y protección, sino más bien reclusión y alienación. Como señala Jesús Carrillo "los hábitos cotidianos y los habitáculos en que estos se producen no articulan ya la vida dándole sentido sino que la introducen en un loop perpetuo del que no hay ya salida posible" (Carrillo, 2004: 138). Las tres 
escaleras que forman parte del atrezzo de la performance, cuyos peldaños han sido sustituidos por cuchillos, evidencian la imposibilidad de romper dicho círculo cotidiano y alienante cuando se refiere a la mujer.

Indudablemente, llegados a este punto, tanto Eulalia Valldosera como Marina Abramovic, despliegan su discurso a través de su enorme poder de seducción, ya sea por la ausencia inquietante de su cuerpo, en el caso de Valldosera, o por la capacidad de atraer la mirada del público, el "aquí y ahora" de su cuerpo, en lo referente a la trayectoria de Abramovic. De ahí que nos hayamos servido de las citadas obras de estas artistas para señalar cómo el espacio de la representación femenina, tanto real como simbólico, niega su enunciación tradicional y apunta a la necesidad de partir de una noción comprensiva en lo relativo a la asociación de conceptos cuerpo-casa/casacuerpo.

\section{CONCLUSIONES}

En las obras de las artistas que hemos señalado existe una reivindicación de la dicotomía público-privado que hace referencia a la mujer. En este sentido, se revalorizan las actividades tradicionales del ama de casa y las tareas domésticas del cuidado del lugar donde se habita, convirtiendo esta liberación en un acto de pasaje que tiene valor en sí mismo.

Persiste, igualmente, una decisión de no objetivar el proceso de subjetivación en los términos de un lenguaje que no se ha configurado desde la experiencia compleja del cuerpo sexuado, del cuerpo erótico o del cuerpo en relación.

Finalmente, podemos corroborar que las obras artísticas femeninas que hemos citado en este texto, son eficaces en la medida que generan un debate en torno a la enunciación tradicional y en lo relativo a la asociación de conceptos cuerpocasa/casa-cuerpo.

\section{BIBLIOGRAFÍA}

LAUB, M. (2004): Marina Abramovic. The Biography of Biographies, Italia, Charta. J.A.RAMIREZ y J. CARRILLO (eds.) (2004): Tendencias del arte, arte de tendencias a principios del siglo XXI, Madrid, Ensayos Arte Cátedra.

JONES, A. (1998): Body Art. Performing the subjects, Minneapolis/London, University of Minnesota Press.

WEISS, G. (1999): Body Images: embodiment as intercorporeality, New York/London, Routledge. 
BASSAS, A. (2001): "Cuerpo que te quiero cuerpo. Imágenes del cuerpo y nociones de subjetividad en la producción de artistas contemporáneas", en M. Azpeitia, M.J. Barral, L.E. Díaz, T. González Cortés, E. Moreno, T. Yago (eds.) Piel que habla. Viaje a través de los cuerpos femeninos, Barcelona, Icaria. 111-138. 